\title{
EVALUATION OF SOME PHYSICO-MECHANICAL PROPERTIES OF COMPOSITE RESINS
}

\author{
H. El Sayed ${ }^{*}$ N. Ibrahim ${ }^{* *}$, M. Samman ${ }^{* * *}$ and A. Elammary ${ }^{* * * *}$
}

\begin{abstract}
This is an in vitro study for evaluation of some physico-mechanical properties for bulk fill and conventional nano hybrid composite resins. Materials and methods: two types of composite resins. Tetric evo Ceram bulk fill and conventional nano hybrid composite (Z250XT) used for measuring polymerization shrinkage and hardness. A total of 120 specimens were prepared and equally divided into two main groups according to test type. Each main group were subdivided into two main subgroups according to the composite resin used. The two main subgroups were subdivided into three class according to storage time in distilled water for 24 hours, 7 days and 30 days. The polymerization shrinkage was measured by computer vision system. Surface microhardness was measured by Vickers hardness tester. Statistical evaluation was performed using two-way analysis of variance ANOVA and tukey's test $(\mathrm{p}<0.05)$. Result: the polymerization shrinkage of Tetric evo Ceram bulk fill is lowered compared to conventional nano hybrid composite resin. Also, Tetric evo Ceram bulk fill has higher hardness than conventional nano hybrid composite resin. Also, storage time had significant effect (30days $>7$ days $>24$ hours). Conclusion: bulk fil composite has good physical and mechanical properties than conventional nano hybrid composite resin. Water storage has significant effect on properties of composite resin.
\end{abstract}

\section{INTRODUCTION}

Increasing interest in esthetic restorations and rising public concern regarding the safety of dental amalgam have produced an increase in the demand for composite resins for posterior restorations ${ }^{(1)}$. The polymerization shrinkage stress remains one of the concerns that contribute to the clinical drawbacks of the resin-based composite materials ${ }^{(2)}$.

The polymerization shrinkage can lead to stress, gaps, discoloration, secondary caries, cracks and increased sensitivity in the restored tooth ${ }^{(3)}$. Attempts have been made to reduce polymerization shrinkage in composite resins by changing the composition of the material ${ }^{(4)}$, using alternative resins, ${ }^{(5)}$ or using various cavity filling technique. ${ }^{(6)}$ These may include the possibility of incorporating voids or contamination between composite layers, bond failures between increments, and the increased time required to place and polymerize each layer ${ }^{(7)}$. There is a direction to decrease the number of increments for composite and support the use of a bulk fill technique. Several manufacturers have developed "bulk fill" composites that can be applied to the cavity in a thickness of $4 \mathrm{~mm}$ with enhanced curing and controlled shrinkage ${ }^{(8)}$. However, there is a few data are Available regarding the properties of bulk fill composite. So, this study will be done to compare bulk fill and nano hybrid composite regarded to some physical and mechanical properties.

\section{MATERIALS AND METHODS}

\section{Materials:}

Two commercially available composite resins with color shade (A2) used in this study. As shown in Table (1)

\footnotetext{
* Demonstrator of Dental Biomaterials Department, Al-Azhar University, (Assiut Branch)

**Assistant Professor in Operative Dentistry Department, Al-Azhar University, Cairo. Egypt

*** Assistant Professor in Dental Biomaterials Department, Al-Azhar University, Cairo,Egypt

**** Lecturer in Operative dentistry Department, Al-Azhar University , (Assiut Branch)
} 
TABLE (1) The materials used in this study

\begin{tabular}{|l|l|l|l|}
\hline \multicolumn{1}{|c|}{ Features } & \multicolumn{1}{|c|}{ Type } & \multicolumn{1}{|c|}{ Composition } & \multicolumn{1}{|c|}{$\begin{array}{c}\text { Manufacturer, Batch number, } \\
\text { website }\end{array}$} \\
\hline $\begin{array}{l}\text { Tetric Evo } \\
\text { Ceram } \\
\text { Bulk Fill }\end{array}$ & Nanohybrid composite & $\begin{array}{l}\text { Matrix :UDMA, (Bis-GMA), } \\
\text { Bis-EMA } \\
\text { Filler: Barium glass, ytterbium trifluoride, mixed } \\
\text { oxide prepolymer } \\
\text { Filler by Weight \% 81 } \\
\text { Filler by Volume \% 79 }\end{array}$ & $\begin{array}{l}\text { Ivoclar } \\
\text { Vivadent, Inc. }\end{array}$ \\
\hline Filtek Z250 XT & $\begin{array}{l}\text { Nanohybrid composite } \\
\text { incremental technique }\end{array}$ & $\begin{array}{l}\text { Matrix: Bis-GMA, UDMA, Bis-EMA, PEGDMA } \\
\text { and TEGDMA. } \\
\text { Filler: Surface-modified zirconia/silica (3micron) } \\
\text { and 20 nm surface-modified Silica. Filler by } \\
\text { weight: (82\%) } \\
\text { Filler by volume: 68\% }\end{array}$ & 3M ESPE/St. Paul, MN, USA \\
\hline
\end{tabular}

\section{Methods:}

\section{1- Grouping of the specimens:}

A total of 120 specimens were prepared and equally divided into two main groups of 60 specimens according to test type. Each main group were subdivided into two main subgroups of 30 specimens according to the composite restorative material used. The two main subgroups will be further subdivided into three class according to Storage time in distilled water ( 24 hours, 7 days and 30 days).

\section{1- Polymerization shrinkage test:}

A rectangular glass slab of dimensions $(50 \times 20$ x $2 \mathrm{~mm}$ ) was used for polymerization shrinkage measurements. A Piece of glass slab $2 \mathrm{~mm}$ in thickness was adhered on the glass slab to create square rooms of dimensions $(5 \times 5 \mathrm{~mm}$ ) for sample preparation. The composite material was packed into the squared areas of the glass mold and cured according to the manufacture instruction by light curing unit (LED). The samples were stored in distilled water and measurement is done at different storage times (24 hours, after 7 days, after30 days). Measurements of polymerization shrinkage done by using digital microscope without directly contacting the samples.
The computer vision system for measuring Polymerization shrinkage consisting of a $1200 \mathrm{x}$ 800 pixel camera (Digital Microscope, Guangdong, China) with $25 \mathrm{x}$ magnification and image analysis software for imaging processing and analysis. Volumetric polymerization shrinkage is obtain

$$
\text { From the equation } \frac{=\Delta \mathrm{L} \times 100}{(\mathrm{Lc}+\mathrm{Lo})}
$$

Where: $\Delta \mathrm{L}=\mathrm{L} 0-\mathrm{Lf}(\mu \mathrm{m}), \mathrm{L} 0=$ the thickness of the uncured specimen $(\mu \mathrm{m}), \mathrm{Lf}=$ the thickness of the specimen after curing $(\mu \mathrm{m}), \mathrm{Lc}=$ step height between the top of the glass mould surface and its bottom (corrective depth) $(\mu \mathrm{m})$.

\section{Surface microhardness test:}

Stainless steel mold was Used to form the specimens with dimensions of $(6 \mathrm{~mm}$ in height $\times 4 \mathrm{~mm}$ in diameter). The composite was packed in the mold and cured by LED light curing unit according to manufacture instructions. The samples were stored in distilled water and measurement is done at different storage times ( 24 hours, after 7 days, after30 days). Surface microhardness of the specimens was determined using Digital Display Vickers Microhardness Tester with a Vickers diamond Indenter and a $20 \mathrm{X}$ objective lens. 
A load of 200 gram was applied to the surface of the specimens for $15 \mathrm{sec}$ three indentations were equally placed over a circle and not closer than 0.5 $\mathrm{mm}$ to the adjacent indentations were made on the surface of each specimen. The diagonals length of the indentations were measured by built in scaled microscope and Vickers values were converted into micro-hardness values. Vickers microhardness was obtained using the following equation: $\mathrm{VHN}=1.854$ $\mathrm{L} / \mathrm{D}^{2}$ Where: VHN: Vickers hardness in $\mathrm{Kg} / \mathrm{mm}^{2}$. And L: Load in $\mathrm{Kg}$ and D: Length of the diagonals in $\mathrm{mm}$.

\section{THE RESULT}

Statistical analysis was performed using Assistant 7.6 statistics software

Polymerization shrinkage test result: Totally regardless to storage time it was For Windows. $\mathrm{P}$ values $\leq 0.05$ are considered to be statistically significant in all tests. Totally regardless to composite resin type it was found that one month subgroup recorded the highest statistically significant mean found that nano-hybrid composite resin recorded statistically significant higher polymerization shrinkage (3.68\%) than bulk Fill composite resin $(2.67 \%)$ value of polymerization shrinkage $(3.73 \%)$ followed by one week subgroup (3.48\%) mean while the lowest statistically significant value was recorded with 24 hrs. subgroup (2.3\%) as shown in table (2).

\section{Microhardness test result:}

Totally regardless to storage time it was found that bulk fill composite resin recorded statistically non-significant higher $(\mathrm{B} / \mathrm{T})$ ratio $(92.89142)$ than nano-hybrid composite resin (88.858). Totally regardless to composite resin type it was found that 24 hrs. Subgroup

Recorded the highest statistically non- significant mean value of $(\mathrm{B} / \mathrm{T})$ ratio $(91.04865)$ followed by one month subgroup (90.90141) mean while the lowest statistically non-significant mean value was recorded with one week subgroup (90.67421) as shown in table (3)

TABLE (2). Comparison of polymerization shrinkage (Mean values \pm SDs) between different storage times with both dental composite resin

\begin{tabular}{|c|c|c|c|c|}
\hline \multicolumn{2}{|c|}{ Variables } & Bulk Fill & Nano-hybrid & t-test \\
\cline { 3 - 5 } & $24 \mathrm{hr}$. & Mean values \pm SDs & Mean values \pm SDs & P value \\
\hline \multirow{3}{*}{ Polymerization shrinkage } & One week & $2.033 \mathrm{~B} \pm 0.28$ & $2.56 \mathrm{~B} \pm 0.75$ & $0.289 \mathrm{~ns}$ \\
\cline { 2 - 5 } & One month & $2.83 \mathrm{~A} \pm 0.56$ & $4.13 \mathrm{~A} \pm 0.35$ & $0.013^{*}$ \\
\hline \multirow{2}{*}{ ANOVA } & P value & $3.133 \mathrm{~A} \pm 0.48$ & $4.33 \mathrm{~A} \pm 0.82$ & $0.05^{*}$ \\
\hline
\end{tabular}

Different letter in the same column indicating statistically significant difference $(p<0.05)$ *;

significant $(p<0.05) n s ;$ non-significant $(p>0.05)$ 
TABLE (3) Vickers $\mu$-hardness results for top, bottom surfaces and $\mathrm{B} / \mathrm{T}$ ratios of both dental composite resins after different storage time

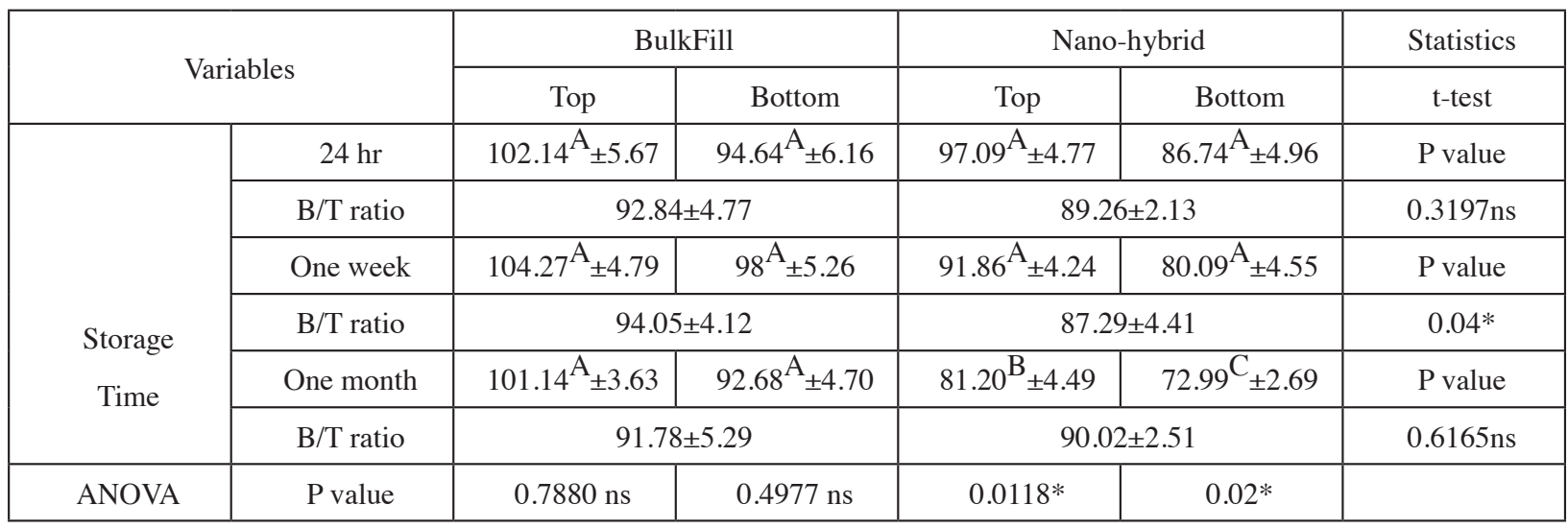

Different letter in the same column indicating statistically significant difference $(p<0.05) *$; significant $(p<0.05) n s ;$ non-significant $(p>0.05)$

\section{DISCUSSION}

The present study was conducted to evaluate some physico-mechanical properties of composite resins using one bulk fill composite resin (tetric evo ceram bulk fill placed in bulk technique) and the other is a conventional nanohybrid composite resin (Z250XT placed in incremental technique) and studied the effect of storage time on these properties.

\section{Polymerization shrinkage}

Polymerization shrinkage of composite resin materials is considered one of the major concerns when placing direct resin-based posterior composite restorations which affect the clinical success of dental composite ${ }^{(9)}$. The polymerization shrinkage can lead to stress, gaps, discoloration , secondary caries, cracks and increased sensitivity in the restored tooth ${ }^{(3)}$.

The results of the present study showed that the polymerization shrinkage of bulk fill composite is lower than the polymerization shrinkage of nanohybrid conventional composite (Z250XT). This may be explained-as the manufacture claimed- newer technology or "polymerization modulators" which allow a certain amount of flexibility and optimized network structure during polymerization ${ }^{(10)}$.
Also the manufacturer claims that the reduced polymerization shrinkage of tetric evo ceram Bulk Fill is achieved by the incorporation of a stress reliever, which keeps the chemical cushion between filler particles intact; this cushion helps to improve the elasticity of the materials and reduces polymerization shrinkage ${ }^{(11)}$

The result of this study showed agreement with El-Damanhoury $\mathrm{H}^{(9)}$, Rosatto $\mathrm{C}$ et al. ${ }^{(12)}$, Garcia $\mathrm{D}^{(13)}$ Fuessle Getal. (2016) ${ }^{(14)}$ they found that the tetric evo Ceram bulk fill contains a shrinkage stress reliever in the form of patented special filler (prepolymer) whose modulus of elasticity is relatively low at $10 \mathrm{GPa}$. This filler acts like a microscopic spring (expanding slightly as the forces between the fillers grow during polymerization) and absorbs the stresses generated during light activation.

Also this study showed agreement with Kleverlaan $\mathrm{CJ}^{(15)}$ who found that the increased filler volume content in high-viscosity bulk-fill composites is reported to be a direct cause for significantly less polymerization shrinkage. The higher filler load reduces the amount of resin in the composite materials and thus decreases the polymerization shrinkage. 
The result of this study disagreement with $\mathrm{Kim}^{(16)}$ who found that the bulk-fill composite and conventional composite exhibited similar polymerization shrinkage stress this could be attributed to a different methodological approach that was used to assess the polymerization shrinkage stresses.

Microhardness

Hardness is a surface mechanical property that indicates the resistance of a material to indentation or penetration which is influenced by several parameters such as the filler characteristics (size, weight, volume) and the chemical composition of the resin ${ }^{(17)}$.

The result of this study showed that the bulk fill composite resin has higher microhardness than nano-hybrid composite resin with non-significant difference.

This may be explained by enhanced photoinitiation system in bulk fill composite resin. It has an initiator booster (Ivocerin-a dibenzoyl germanium compound) that increasing the depth of cure and degree of polymerization and hardness. ${ }^{(18)}$.

Beun S et al. ${ }^{(19)}$ who found that an increase in the filler concentration of resin composites is associated with an increase in certain properties such as hardness, elastic modulus and flexural strength.

This study showed agreement with Abughufa $\mathrm{H}^{(20)}$, AL-mansour K ${ }^{(21)}$, Farahat F (2016) ${ }^{(22)}$ Alshali RZ (2015) ${ }^{(23)}$ they found that the difference in micro-hardness between bulk fill and conventional composite may be attributed to composition of the organic matrix or increased particle size or using other photo initiators such as Ivocerin

This study showed discordance with study done by Son $\mathrm{BH}^{(24)}$ who found micro hardness decreased with increasing thickness of material. Since bulk fill is applied in single increment at $4 \mathrm{~mm}$ thickness according to the manufacture also Kim E-H et al. ${ }^{(25)}$ found the same result. Also may be attributed to different in materials and methods used.
Effect of storage time on some physico-mechanical properties of composite resins.

Water sorption of resin composites is described as diffusion controlled process that may cause chemical degradation of the material leading to several drawbacks such as de-bonding of the filler polymer-matrix and release of the residual unreacted monomers. On the other hand, water solubility of resin composites is reflected by the amount of leached unreacted monomers and the subsequent loss of filler particle ${ }^{(26)}$.

This study show gradual increase in polymerization shrinkage and gradual decrease in hardness for bulk fill conventional nanohybrid composite resin when stored in distal water for 7 days and 30 days. The gradual Increase in polymerization shrinkage may be explained by low degree of water sorption by bulk fill and conventional composite. Dimensional changes i.e. Shrinkage of a resin composite in water is mainly attributed to leaching of free residual monomers, additives, fillers and filler components ${ }^{(27)}$.

This study showed that at 7 days the hardness of bulk fill and conventional composite is increased. This is may be attributed to the continuation of the polymerization process in composite resin at a slow rate $^{(20)}$. Also, may be attributed to a progressive increase in cross linking in addition to postirradiation polymerization reaction ${ }^{(23)}$.

The gradual decrease in hardness from 7 days to 30 days when stored in distilled water may be attributed to water sorption and degradation of the material ${ }^{(20)}$.

The result of this study showed agreement with Curtis et al. in ${ }^{(28)}$, Medeiros et al. in ${ }^{(29)}$ they found that the increase water uptake for composite resin may be attributed to the larger surface area to volume ratio of the fillers present in the materials. Also tend to increase the water uptake and resultant degradation of the filler/matrix interface. 
Also this study showed agreement with Musanje et al. in ${ }^{(30)}$ who found that the water sorption decreased the values of mechanical properties of resin composite due to plasticizing and hydrolytic degradation of monomer which is a diffusion - rate dependent process influenced by type of polymer, filler particle type and surface treatment used. The absorbed water may also react with the coupling agent resulting in the failure of the filler-matrix bond. Thus, leaching of monomer from the composite into the oral environment and water replacement to fill the holes left by eluting monomers or oligomers might have contributed to the more weakening effect.

Also From this study we found that the water sorption and solubility of composite resins was increased with increased storage time ${ }^{(31)}$.

The present study showed disagreement with Fan et al. ${ }^{(32)}$ who found water sorption is a slow process and may not reach equilibrium even after 30 days and require longer storage time.

\section{CONCLUSION}

From this study the following conclusions may be drawn:

Bulk fill composite resins have lower polymerization shrinkage and high hardness than conventional nanohybrid composite resin. Also, storage times have significant effect on some physico-mechanical properties of bulk Fill composite and conventional nanohybrid Composite resin. More studies should be conducted to evaluate other properties of these materials and the effect of extending the period of storage time from 3-6 months also further vivo study should be carried out to confirm this result.

\section{REFERENCES}

1. Karaman E, Ozgunaltay G. Cuspal deflection in premolar teeth restored using current composite resins with and without resin-modified glass ionomer liner. Operative Dentistry. 2013;38(3):282-9.
2. Jafarpour S, El-Badrawy W, Jazi H, McComb D. Effect of composite insertion technique on cuspal deflection using an in vitro simulation model. Operative Dentistry. 2012;37(3):299-305.

3. Anusavice KJ, Shen C, Rawls HR. Phillips' science of dental materials: Elsevier Health Sciences; 2013;23(4):23-25.

4. Satterthwaite JD, Maisuria A, Vogel K, Watts DC. Effect of resin- composite filler particle size and shape on shrinkage-stress. Dental Materials. 2012;28(6):609-14.

5. Cramer N, Stansbury J, Bowman C. Recent advances and developments in composite dental restorative materials .Journal of Dental Research. 2011;90(4):402-16.

6. Soares CJ, Bicalho AA, Tantbirojn D, Versluis A. Polymerization shrinkage stresses in a premolar restored with different composite resins and different incremental techniques. Journal Adhesion Dentisty . 2013;15(4):34-1.50

7. Sarrett DC. Clinical challenges and the relevance of materials testing for posterior composite restorations. Dental Materials. 2005;21(1):9-20.

8. Ilie N, Hickel R. Investigations on a methacrylate-based flowable composite based on the $\mathrm{SDR}^{\mathrm{TM}}$ technology. Dental Materials. 2011;27(4):348-55.

9. El-Damanhoury H, Platt J. Polymerization shrinkage stress kinetics and related properties of bulk- fill resin composites. Operative Dentistry. 2014;39(4):374-82.

10. Surefil S. flow Product Dentsply International. 2013.

11. Vivadent I. Tetric EvoCeram Bulk fill: simplifies composite restoration placement, increases efficiency. Dental Materials. 2014;35(6):432.

12. Rosatto C, Bicalho A, Veríssimo C, Bragança G, Rodrigues $\mathrm{M}$, Tantbirojn D, et al. Mechanical properties, shrinkage stress, cuspal strain and fracture resistance of molars restored with bulk-fill composites and incremental filling technique. Journal of Dentistry. 2015;43(12):1519-28

13. Garcia D, Yaman P, Dennison J, Neiva G. Polymerization shrinkage and depth of cure of bulk fill flowable composite resins. Operative Dentistry. 2014;39(4):441-8.

14. Fuessle G, Oghale E, Chen L, Suh B. Depth of cure and bond strength of bulk-fill composite. Dental Materials. 2016;3(32):33-39.

15. Kleverlaan CJ, Feilzer AJ. Polymerization shrinkage and contraction stress of dental resin composites. Dental Materials. 2005;21(12):1150-7.

16. Kim RJ-Y, Kim Y-J, Choi N-S, Lee I-B. Polymerization shrinkage, modulus, and shrinkage stress related to tooth- 
restoration interfacial debonding in bulk-fill composites. Journal of Dentistry. 2015;43(4):430-9.

17. Scougall-Vilchis RJ, Hotta Y, Hotta M, Idono T, Yamamoto K. Examination of composite resins with electron microscopy, microhardness tester and energy dispersive X-ray microanalyzer. Dental Materials Journal. 2009;28(1):102-12.

18. Alrahlah A, Silikas N, Watts D. Post-cure depth of cure of bulk fill dental resin-composites. Dental Materials. 2014;30(2):149-54.

19. Beun S, Glorieux T, Devaux J, Vreven J, Leloup G. Characterization of nanofilled compared to universal and microfilled composites. Dental Materials. 2007;23(1):51-9.

20. Abughufa H. Micro-hardness and depth of cure of dental bulk-fill composites. 2015;34(4):23-7.

21. AL-mansour K, AL-sada A, AL-sinan H. curing depth of bulk-fill composites-an in-vitro study. Pakistan Oral \& Dental Journal. 2015;35(2):56-58.

22. Farahat F, Daneshkazemi A, Hajiahmadi Z. The Effect of Bulk Depth and Irradiation Time on the Surface Hardness and Degree of Cure of Bulk-Fill Composites. Journal of Dental Biomaterials. 2016;3(3):12-15.

23. Alshali RZ, Salim NA, Satterthwaite JD, Silikas N. Postirradiation hardness development, chemical softening, and thermal stability of bulk-fill and conventional resincomposites. Journal of Dentistry. 2015;43(2):209-18.

24. Son BH, Kwon Y-H, Park J-K. Effect of resin thickness on the microhardness and optical properties of bulk-fill resin composites. 2014;34(6):45-48.
25. Kim E-H, Jung K-H, Son S, Hur B, Kwon Y-H, Park J-K Effect of resin thickness on the microhardness and optical properties of bulk-fill resin composites. Restorative Dentistry \& Endodontics. 2015;40(2):128-35.

26. Giannini M, Di Francescantonio M, Pacheco R, Boaro LC, Braga R. Characterization of water sorption, solubility, and roughness of silorane-and methacrylate-based composite resins. Operative Dentistry. 2014;39(3):264-72

27. Van Landuyt K, Nawrot T, Geebelen B, De Munck J, Snauwaert J, Yoshihara K, et al. How much do resin- based dental materials release? A meta- analytical approach. Dental Materials. 2011;27(8):723-47.

28. Curtis A, Shortall A, Marquis P, Palin W. Water uptake and strength characteristics of a nanofilled resin- based composite. Journal of Dentistry. 2008;36(3):186-93

29. Medeiros IS ,Gomes MN, Loguercio AD, Filho LE. Diametral tensile strength and Vickers hardness of a composite after storage in different solutions. Journal of Oral Science. 2007;49(1):61-6.

30. Musanje L, Shu M, Darvell B. Water sorption and mechanical behaviour of cosmetic direct restorative materials in artificial saliva. Dental Materials. 2001;17(5):394-401.

31. Sideridou I, Tserki V, Papanastasiou G. Study of water sorption, solubility and modulus of elasticity of lightcured dimethacrylate- based dental resins .Biomaterials. 2003;24(4):655-65.

32. Fan P, Edahl A, Leung R, Stanford J. Alternative interpretations of water sorption values of composite resins. Journal of Dental Research. 1985;64(1):78-80. 
